\title{
EFFECTS OF ANNEALING TEMPERATURE ON THE CRYSTALLOGRAPHIC, MORPHOLOGICAL AND ELECTRICAL CHARACTERISTICS OF E-BEAM DEPOSITED AI/Eu $\mathrm{O}_{3} / \mathrm{N}-\mathrm{Si}$ (MOS) CAPACITORS
}

\author{
Ozan Yilmaz ${ }^{1,2}$, Ercan Yilmaz, ${ }^{1,{ }^{*}}$ \\ ${ }^{1}$ Physics Department, Bolu Abant Izzet Baysal University, Bolu, Turkey \\ ${ }^{2}$ Nuclear Radiation Detectors Application and Research Center (NÜRDAM), Bolu Abant Izzet Baysal University, Bolu, \\ Turkey
}

\begin{abstract}
Rare earth oxides (REOs) play an important role in the semiconductor technology. Europium oxide $\left(\mathrm{Eu}_{2} \mathrm{O}_{3}\right)$ is one of $\mathrm{REO}$ and it has been used in many applications such as optoelectronics, telecommunications, microelectronics and optical devices. However, in this study, $\mathrm{Eu}_{2} \mathrm{O}_{3} \mathrm{MOS}$ capacitors have been fabricated by using the Electron Beam Evaporation (E-Beam) technique and the effects of different annealing temperatures on them have been investigated. Before and after annealing, the crystallographic and morphological properties of the $\mathrm{Eu}_{2} \mathrm{O}_{3}$ films have been analyzed by X-ray Diffraction and Atomic Force Microscopy. The electrical properties of the devices have been investigated using measuring $C-V, G / \omega-V$ characteristics. This preliminary study shows that Europium oxide can be suitable for application as a thin film.
\end{abstract}

Keywords: Europium Oxide, MOS structure, Capacitance-Voltage, Conductance-Voltage

\section{INTRODUCTION}

Metal-oxide-semiconductor (MOS) capacitors have a very important role in microelectronic applications [1]. The $\mathrm{SiO}_{2}$ layer is conventionally used in MOSbased devices [1], [2]. However, for the last few decades, rare earth oxides (REOs), such as $\mathrm{Er}_{2} \mathrm{O}_{3}$, $\mathrm{Yb}_{2} \mathrm{O}_{3}, \mathrm{Gd}_{2} \mathrm{O}_{3}, \mathrm{Dy}_{2} \mathrm{O}_{3}$, and $\mathrm{Y}_{2} \mathrm{O}_{3}$ [3]-[8], draw attention in the field of microelectronics. The REOs have lots of properties that can be used as a gate dielectric when their performance compares with $\mathrm{SiO}_{2}$. Among those properties are wide bandgap $\left(\mathrm{E}_{\mathrm{g}}=4-6 \mathrm{eV}\right)$, high dielectric constant $(\varepsilon=7-20)$, high recrystallization temperature, thermodynamic stability, high-quality interface with $\mathrm{Si}$ with low interfacial state density, and lower leakage conduction than $\mathrm{SiO}_{2}$ at an equivalent oxide thickness. Europium oxide $\left(\mathrm{Eu}_{2} \mathrm{O}_{3}\right)$ is one of REOs and it has features such as high dielectric constant $(\varepsilon=14)$ [9], large energy band gap $\left(\mathrm{E}_{\mathrm{g}}=4.4 \mathrm{eV}\right)$ [10], [11], high chemical durability and thermal stability [12]. In the account of these properties, $\mathrm{Eu}_{2} \mathrm{O}_{3}$ has some advantages compared to a silicon dioxide $\left(\mathrm{SiO}_{2}\right)$ as a gate dielectric in many applications such as optoelectronics, telecommunications, microelectronics, and optical devices [9].

In this study, $\mathrm{Eu}_{2} \mathrm{O}_{3}$ MOS capacitors have been fabricated by using the Electron Beam Evaporation (E-Beam) technique and the effects of different annealing temperatures on them have been investigated. The $\mathrm{C}-\mathrm{V}$ and $\mathrm{G} / \omega-\mathrm{V}$ measurements of the generated $\mathrm{Eu}_{2} \mathrm{O}_{3}$ MOS capacitor were measured at $1 \mathrm{MHz}$.

\section{EXPERIMENTAL PROCEDURE}

Europium oxide thin film was deposited onto a $500 \mu \mathrm{m}$ thick n-type silicon (n-Si) wafer with a resistivity of 2-4 $\Omega \mathrm{cm}$ by the E-Beam deposition technique. Before the deposition of the oxides, the wafer was cleaned by following the standard radio corporation of America's (RCA) cleaning procedures. The 99.99\% pure $\mathrm{Eu}_{2} \mathrm{O}_{3}$ granules were used as target material during the film deposition. The base chamber pressure and the substrate temperature were adjusted to below $7.4 \times 10-4 \mathrm{~Pa}$ and $150^{\circ} \mathrm{C}$, respectively, before the $\mathrm{Eu}_{2} \mathrm{O}_{3}$ deposition. The thickness of the europium oxide is approximately determined to be $40 \mathrm{~nm}$ with the Spectroscopic Ellipsometer (AngstromSun Technology-Sr100). Then, this wafer was cut into five pieces. One of them was kept as deposited and the others were annealed at $300^{\circ} \mathrm{C}, 500^{\circ} \mathrm{C}, 700^{\circ} \mathrm{C}$, and $900^{\circ} \mathrm{C}$ in a $\mathrm{N}_{2}$ environment for $40 \mathrm{~min}$, respectively. The chemical characteristics of the $\mathrm{Eu}_{2} \mathrm{O}_{3} / \mathrm{n}-\mathrm{Si}$ structure were determined by a Perkin Elmer Spectrum Two FTIR-ATR (Fourier Transform InfraRed Attenuated Total Reflectance) spectrophotometer. The crystallographic of $\mathrm{Eu}_{2} \mathrm{O}_{3}$ thin film was analyzed by a Rigaku Multiflex diffractometer employing $\mathrm{CuKa}$ radiation while the morphological change of $\mathrm{Eu}_{2} \mathrm{O}_{3}$ thin film depending on annealing temperatures was studied by Atomic Force Microscopy.

*yilmaz@ibu.edu.tr 
In order to make the front and back contacts of these devices (Fig.1), the aluminum (Al 99.999\%) sputter target was used. The process and sputtering pressures were adjusted below $7.0 \times 10-4$, and $1 \mathrm{~Pa}$, respectively. The capacitance-voltage and conductance-voltage for the fabricated $\mathrm{Al} / \mathrm{Eu}_{2} \mathrm{O}_{3} / \mathrm{n}-\mathrm{Si}$ MOS capacitors were obtained at $1 \mathrm{MHz}$ at room temperature using Impedance Analyzer (MODEL HIOKI 3532-50 LCR meter).

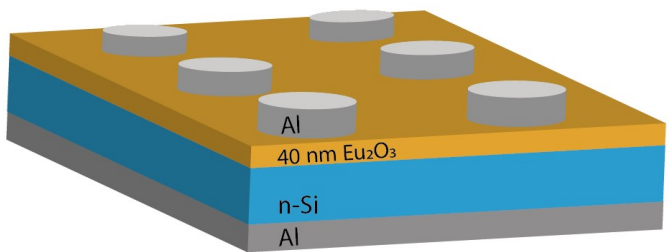

Figure 1. Schematic structure of the $\mathrm{Al} / \mathrm{Eu}_{2} \mathrm{O}_{3} / \mathrm{n}-\mathrm{Si} / \mathrm{Al}$ MOS capacitor.

\section{RESULTS AND DISCUSSION}

\subsection{FTIR, $X R D$, and $A F M$ results}

The FTIR spectrum of $\mathrm{Eu}_{2} \mathrm{O}_{3}$ on $\mathrm{Si}$ after annealing at as-deposited and different temperatures can be seen as Figure 2. The peaks (at $2335 \mathrm{~cm}^{-1}, 2100 \mathrm{~cm}^{-1}$, $1992 \mathrm{~cm}^{-1}, 1240 \mathrm{~cm}^{-1}$, and $1110 \mathrm{~cm}^{-1}$ ) of $\mathrm{Eu}_{2} \mathrm{O}_{3}$ thin films are getting smaller with increasing of annealing temperature, while it is observed that some small peaks emerge between $840 \mathrm{~cm}^{-1}$ and $700 \mathrm{~cm}^{-1}$. These peaks are related to the Eu-O bending modes[13], [14].

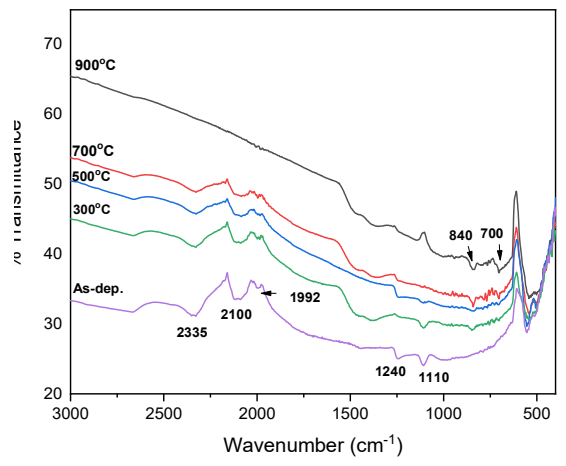

Figure 2. FTIR spectra of $\mathrm{Eu}_{2} \mathrm{O}_{3} / \mathrm{Si}$ thin films at different annealing temperatures.

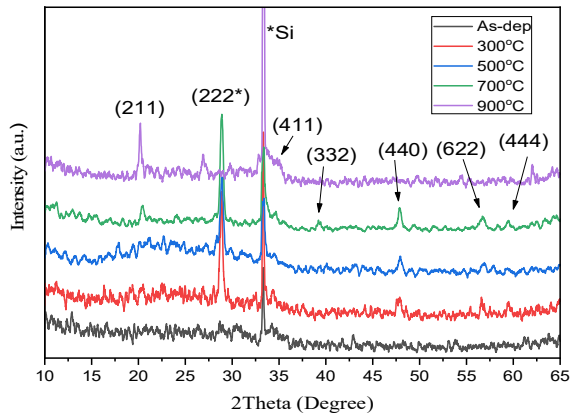

Figure 3. The XRD pattern of the $\mathrm{Eu}_{2} \mathrm{O}_{3} / \mathrm{Si}$ structure asdeposited and annealed at $300{ }^{\circ} \mathrm{C}, 500{ }^{\circ} \mathrm{C}, 700{ }^{\circ} \mathrm{C}, 900{ }^{\circ} \mathrm{C}$.
The diffraction patterns of the annealed thin films (Fig. 3) can be indexed to the cubic phase, which is consistent with the values in the standard card (JSPDS no. 34-0392, quality «*», a value of $10.86 \mathrm{~nm}$ ) [15], [16]. The grain size (D) of the film was calculated using Debye-Scherrer formula [17].

$$
D=\frac{0.9 * \lambda}{\beta \cos \theta}
$$

The values of grain size and crystallinity of the films increase with the increasing annealing temperatures, except for $900^{\circ} \mathrm{C}$ annealed sample[18], [19] (Table 1).

Table 1. Grain size (nm), Crystallinity (\%), and RMS Roughness (nm) of deposited $\mathrm{Eu}_{2} \mathrm{O}_{3} / \mathrm{Si}$ depend on annealing.

\begin{tabular}{cccc}
\hline $\begin{array}{c}\text { Annealing } \\
\text { Temp. }\left({ }^{\circ} \mathbf{C}\right)\end{array}$ & $\begin{array}{c}\text { Grain } \\
\text { size } \\
(\mathbf{n m})\end{array}$ & $\begin{array}{c}\text { Crystallinity } \\
\text { (\%) }\end{array}$ & $\begin{array}{c}\text { RMS } \\
\text { Roughness } \\
\text { (nm) }\end{array}$ \\
\hline As-deposited & - & - & 0.135 \\
300 & 23.69 & 15.70 & 0.156 \\
500 & 24.28 & 15.81 & 0.200 \\
700 & 26.45 & 29.39 & 0.238 \\
900 & 12.15 & 18.01 & 0.664 \\
\hline
\end{tabular}
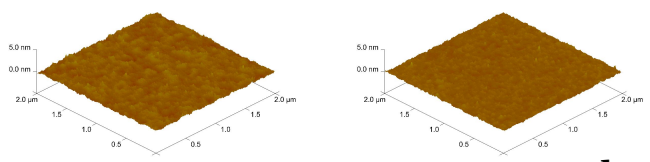

$\mathbf{a}$

b
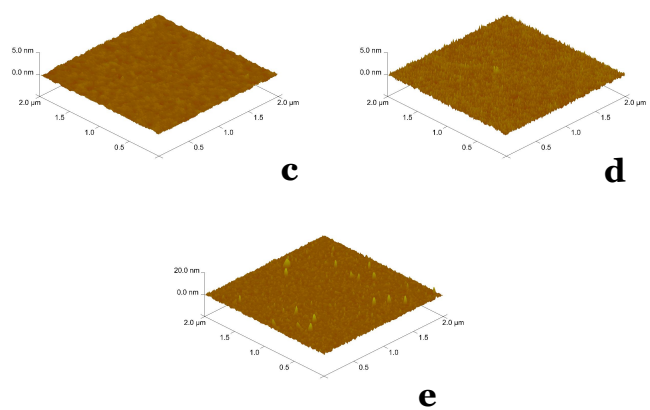

Figure 4. The AFM pictures of the $\mathrm{Eu}_{2} \mathrm{O}_{3} / \mathrm{Si}$ structure a) as- deposited and annealed at

b) $300{ }^{\circ} \mathrm{C}$, c) $500{ }^{\circ} \mathrm{C}$, d) $700{ }^{\circ} \mathrm{C}$, e) $900{ }^{\circ} \mathrm{C}$.

The effects of annealing temperature on the surface morphology of the $\mathrm{Eu}_{2} \mathrm{O}_{3}$ thin films were investigated by AFM measurements (Fig. 5). Although there is no obvious effect of the annealing in the obtained measurements, the slight rises in the root-mean-square (RMS) roughness that have been observed by calculating in the AFM analysis program (Table 1) [12], [20].

\subsection{Electrical characteristics results}

The electrical properties of $\mathrm{Eu}_{2} \mathrm{O}_{3} \mathrm{MOS}$ capacitor were investigated by capacitance-voltage and conductance-voltage measurements at the $1 \mathrm{MHz}$ (Fig. 5, a and b). The graphs of the $\mathrm{C}-\mathrm{V}$ and $\mathrm{G} / \mathrm{w}-\mathrm{V}$ analyses show an increasing trend with the increasing annealing temperature up to the annealed sample at $900{ }^{\circ} \mathrm{C}$. This phenomenon can appear because of the 
recovery of stoichiometry that results in the reduction of structural defects [21], [22]. On the other hand, the condition of the sample annealed at $900{ }^{\circ} \mathrm{C}$ can be owing to the phase transition depending on the annealing temperature [19], [23].
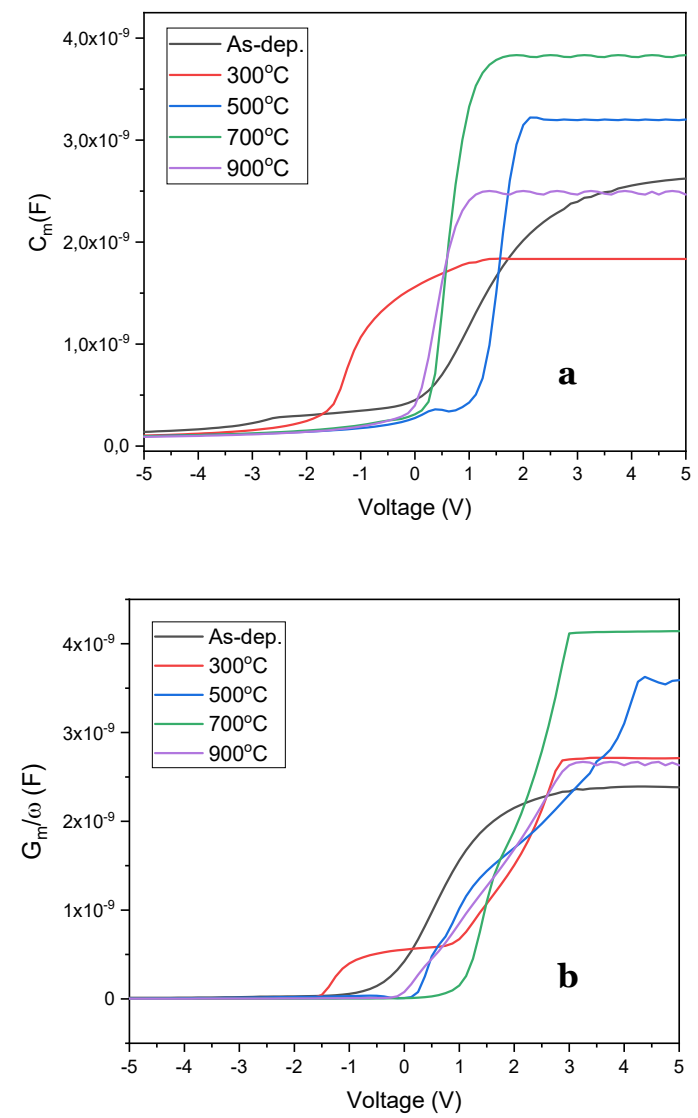

Figure 5. The electrical (a) $\mathrm{C}-\mathrm{V}$ and (b) $\mathrm{G} / \omega-\mathrm{V}$ characteristics of $\mathrm{Al} / \mathrm{Eu}_{2} \mathrm{O}_{3} / \mathrm{Si} / \mathrm{Al} \mathrm{MOS}$ capacitors at $1 \mathrm{MHz}$.

\section{CONCLUSION}

In this study, $\mathrm{Eu}_{2} \mathrm{O}_{3}$ MOS capacitors have been fabricated by using the Electron Beam Evaporation (E-Beam) technique. The effects of different annealing temperatures on them have also been investigated. The crystallinity of $\mathrm{Eu}_{2} \mathrm{O}_{3}$ thin films is sensitive to the annealing, while the grain size of films slightly increases with annealing temperature increase. The results of ATR-FTIR measurements show some changes in the structure of $\mathrm{Eu}_{2} \mathrm{O}_{3}$ thin film because of the annealing. The process of annealing was caused by a small increase in the RMS values of $\mathrm{Eu}_{2} \mathrm{O}_{3}$ thin films found using AFM analysis. The annealing has been shown to be effective on the electrical properties of the $\mathrm{Eu}_{2} \mathrm{O}_{3}$ MOS capacitor. The measurement capacitance and the measurement conductance of $\mathrm{Eu}_{2} \mathrm{O}_{3}$ MOS capacitors increase with the annealing temperature increase.

The results show that $\mathrm{Eu}_{2} \mathrm{O}_{3}$ rare earth materials can be good candidates for microelectronic applications, but more detailed research is required on this rare earth oxide.
Acknowledgements: This work is supported by the Presidency of Turkey, Presidency of Strategy and Budget under Contract Number 2016 K 12-2834.

\section{REFERENCES}

[1] S. M. Sze, K. K. Ng, Physics of Semiconductor Devices, 3rd ed., Hoboken (NJ), USA: J. Wiley and Sons, 2007.

DOI: $10.1002 / 9780470068328$.fmatter

[2] H. Ono, T. Katsumata, "Interfacial reactions between thin rare-earth-metal oxide films and Si substrates," Appl. Phys. Lett., vol. 78, no. 13, pp. $1832-1834$, 2001.

DOI: $10.1063 / 1.1357445$

[3] S. Kaya, E. Yilmaz, "Modifications of structural, chemical, and electrical characteristics of $\mathrm{Er}_{2} \mathrm{O}_{3} / \mathrm{S}$ interface under Co-60 gamma irradiation," Nucl. Instrum. Methods Phys. Res. B, vol. 418, pp. $74-79$, Mar. 2018.

DOI: 10.1016/j.nimb.2018.01.010

[4] A. Kahraman, H. Karacali, E. Yilmaz, "Impact and origin of the oxide-interface traps in $\mathrm{Al} / \mathrm{Yb} 2 \mathrm{O}_{3} / \mathrm{n}$ $\mathrm{Si} / \mathrm{Al}$ on the electrical characteristics," J. Alloys Compd., vol. 825, article no. 154171, Jun. 2020.

DOI: 10.1016/j.jallcom.2020.154171

[5] A. Kahraman, "Understanding of post deposition annealing and substrate temperature effects on structural and electrical properties of $\mathrm{Gd}_{2} \mathrm{O}_{3} \mathrm{MOS}$ capacitor," J. Mater. Sci. Mater. Electron., vol. 29, no. 1, pp. 7993 - 8001, May 2018.

DOI: $10.1007 / \mathrm{s} 10854-018-8804-\mathrm{y}$

[6] A. Kahraman, S. C. Deevi, E. Yilmaz, "Influence of frequency and gamma irradiation on the electrical characteristics of $\mathrm{Er}_{2} \mathrm{O}_{3}, \mathrm{Gd}_{2} \mathrm{O}_{3}, \mathrm{Yb}_{2} \mathrm{O}_{3}$, and $\mathrm{HfO}_{2}$ MOS-based devices," J. Mater. Sci., vol. 55, no. 81, pp. $7999-8040$, Jul. 2020.

DOI: $10.1007 / \mathrm{s} 10853-020-04531-8$

[7] U. Gurer, O. Yilmaz, H. Karacali, S. Kaya, E. Yilmaz, "Co-6o gamma radiation influences on the electrochemical, physical and electrical characteristics rare-earth dysprosium oxide (Dy2O3)," Radiat. Phys. Chem., vol. 171, article no. 108684, Jun. 2020.

DOI: 10.1016/j.radphyschem.2020.108684

[8] S. Abubakar, S. Kaya, H. Karacali, E. Yilmaz, "The gamma irradiation responses of yttrium oxide capacitors and first assessment usage in radiation sensors," Sens. Actuator A Phys., vol. 258, pp. $44-48$, May 2017.

DOI: 10.1016/j.sna.2017.02.022

[9] S. Kumar, R. Prakash, V. Singh, "Synthesis, Characterization, and Applications of Europium Oxide: A Review," Rev. Adv. Sci. Eng., vol. 4, no. 4, pp. 247 - 257, Dec. 2016.

DOI: 10.1166/rase.2015.1102

[10] L. Petit, A. Svane, Z. Szotek, W. M. Temmerman, "First-principles study of rare-earth oxides," Phys. Rev. B, vol. 72, no. 20, pp. 1 - 9, Nov. 2005.

DOI: 10.1103/PhysRevB.72.205118

[11] M. P. Singh, S. A. Shivashankar, "Structural and optical properties of polycrystalline thin films of rare earth oxides grown on fused quartz by low pressure MOCVD," J. Cryst. Growth, vol. 276, no. 1 - 2, pp. 148 - 157, Mar. 2005.

DOI: 10.1016/j.jcrysgro.2004.11.325

[12] S. A. Lourenço et al., "Eu3+ photoluminescence enhancement due to thermal energy transfer in Eu2O3-doped $\mathrm{SiO}_{2}-\mathrm{B}_{2} \mathrm{O}_{3}-\mathrm{PbO} 2$ glasses system," $J$. Lumin., vol. 131, no. 5, pp. 850 - 855, May 2011. DOI: $10.1016 /$ j.jlumin.2010.11.028

[13] J. G. Kang, Y. Jung, B. K. Min, Y. Sohn, "Full characterization of $\mathrm{Eu}(\mathrm{OH})_{3}$ and $\mathrm{Eu}_{2} \mathrm{O}_{3}$ nanorods," Appl. Surf. Sci., vol. 314, pp. 158 - 165, Sep. 2014. 
DOI: 10.1016/j.apsusc.2014.06.165

[14] M. Majumder, R. B. Choudhary, A. K. Thakur, U. Kumar, "Augmented gravimetric and volumetric capacitive performance of rare earth metal oxide (Eu2O3) incorporated polypyrrole for supercapacitor applications," J. Electroanal. Chem., vol. 804, pp. $42-52$, Nov. 2017.

DOI: 10.1016/j.jelechem.2017.09.048

[15] S. Mukherjee, C. H. Chen, C. C. Chou, H. D. Yang, "Anomalous dielectric behavior in nanoparticle Eu2O3: $\mathrm{SiO} 2$ glass composite system," EPL, vol. 92, no. 5, article no. 57010, Dec. 2010.

DOI: 10.1209/0295-5075/92/57010

[16] Z. Mo, Y. Zhao, R. Guo, P. Liu, T. Xie, "Preparation and characterization of graphene/europium oxide composites," Mater. Manuf. Process., vol. 27, no. 5, pp. $494-498,2012$.

DOI: $10.1080 / 10426914.2011 .593241$

[17] B. D. Cullity, Elements of X-ray diffraction, 2nd ed., Boston (MA), USA: Addison-Wesley, 1978.

Retrieved from:

http://library.lol/main/5F3BD811A44EEDFB22943 BC771EF49F8

Retrieved on: Jan. 24, 2019

[18] A. A. Dakhel, "Poole-Frenkel electrical conduction in europium oxide films deposited on $\mathrm{Si}(100)$," Cryst.

Res. Technol., vol. 38, no. 11, pp. 968 - 973, Nov. 2003.

DOI: $10.1002 /$ crat.200310122
[19] M. P. Singh, K. Shalini, S. A. Shivashankar, G. C. Deepak, N. Bhat, "Structural and electrical properties of low pressure metalorganic chemical vapor deposition grown $\mathrm{Eu}_{2} \mathrm{O}_{3}$ films on $\mathrm{Si}(100)$," Appl. Phys. Lett., vol. 89, no. 20, article no. 201901, Nov. 2006.

DOI: $10.1063 / 1.2388128$

[20] S. Kumar, R. Prakash, R. J. Choudhary, D. M. Phase, "Structural, morphological and electronic properties of pulsed laser grown Eu2O3 thin films," in Proc. 2nd Int. Conf. Condensed Matter And Applied Physics (ICC 2017), Bikaner, India, 2018, pp. 3 - 8. DOI: $10.1063 / 1.5032948$

[21] H. Nakane, A. Noya, S. Kuriki, G. Matsumoto, "Dielectric properties of europium oxide films," Thin Solid Films, vol. 59, no. 3, pp. 291 - 293, May 1979.

DOI: 10.1016/0040-6090(79)90438-3

[22] M. K. Jayaraj, C. P. G. Vallabhan, "Dielectric and optical properties of europium oxide films," Thin Solid Films, vol. 177, no. 1 - 2, pp. 59 - 67, Oct. 1989.

DOI: 10.1016/0040-6090(89)90556-7

[23] P. Zhang et al., "Preparation and Magnetic Properties of Polycrystalline Eu2O3 Microwires," $J$. Electrochem. Soc., vol. 159, no. 4, pp. D204-D207, Jan. 2012.

DOI: $10.1149 / 2.047204 j \mathrm{jes}$ 